\title{
Molecular characterization and resistance profile of nosocomial Acinetobacter baumannii in intensive care unit of tertiary care hospital in Bangladesh
}

\author{
Khatun $\mathrm{MN}^{1}$, Farzana $\mathrm{R}^{2}$, Lopes $\mathrm{BS}^{3}$, Shamsuzzaman $\mathrm{SM}^{4}$ \\ ${ }^{I}$ Department of Microbiology, Shaheed Tajuddin Ahmed Medical College, Gazipur, Bangladesh, \\ ${ }^{2}$ Department of Microbiology, Khwaja Yunus Ali Medical College, Enayetpur, Sirajganj, Bangladesh, \\ ${ }^{3}$ Department of Medical Microbiology, School of Medicine and Dentistry, Room 0: 017, Polwarth \\ Building, University of Aberdeen, Aberdeen AB25 2ZD, United Kingdom, ${ }^{4}$ Department of \\ Microbiology, Dhaka Medical College, Dhaka, Bangladesh. \\ Email: refath_farzana@yahoo.com
}

\begin{abstract}
This study was designed to investigate the resistance profile along with the genetic background of resistance to beta-lactam antibiotics among the nosocomial A. baumannii in Bangladesh. A.

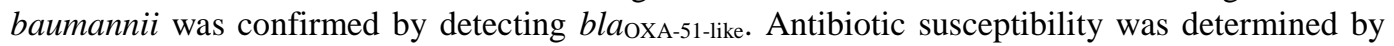
disk diffusion method. Agar dilution method was used to determine MIC of ceftazidime and imipenem. All A. baumannii were phenotypically screened for ampC, ESBL and MBL production.

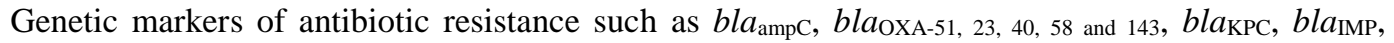
$b l a_{\mathrm{VIM}}$ and $b l a_{\mathrm{NDM}-1}$, genetic environment around $b l a_{\mathrm{ADC}}$ and ISAbal upstream of bla $a_{\mathrm{OXAs}}$ were evaluated by PCR. Twenty-four (96\%) A. baumannii were considered as MDR. 96\% A. baumannii were resistant to amoxiclav, ceftazidime, ciprofloxacin and cefoxitin, 92\% to cefotaxime and piperacillin-tazobactam, $88 \%$ to cefepime, amikacin and imipenem, 52\% to sulbactamcefoperazone and $40 \%$ were resistant to aztreonam. All were sensitive to colistin. The distribution of several beta-lactamase genes such as bla $a_{\text {OXA-51 }}(100 \%), b_{\text {ADC-like }}(92 \%), b l a_{\mathrm{NDM}-1}(92 \%)$, EBC group (84\%), bla $a_{\mathrm{OXA}-23}(76 \%)$, bla $a_{\mathrm{VIM}}(72 \%)$, bla $a_{\mathrm{KPC}}(44 \%)$, DHA group $(24 \%)$, bla $_{\mathrm{OXA}-58}(16 \%)$, ACC group (8\%) and CIT group (4\%) were observed among the $25 \mathrm{~A}$. baumannii. This is the first reported plasmid mediated ampC beta-lactamases in A. baumannii. bla $a_{\text {OXA-51 }}$ was positive in $100 \%$, $b l a_{\mathrm{NDM}-1}$ in $95.45 \%, b l a_{\mathrm{OXA}-23}$ in $77.27 \%$, bla $a_{\mathrm{VIM}}$ in $72.73 \%$, bla $_{\mathrm{KPC}}$ in $50 \%$ and $b l a_{\mathrm{OXA}-58}$ in $18.18 \%$ of imipenem resistant isolates. MDR profile of nosocomial A. baumannii would highlight the importance of standard guideline of antimicrobials use and infection control policy in the hospitals of Bangladesh.
\end{abstract}

Key words: Acinetobacter baumannii, Antimicrobial resistance, Bangladesh, metallo-betalactamase, ampC beta-lactamase, New-Delhi metallo-beta-lactamase-1

\section{Introduction}

Multidrug resistant (MDR) Acinetobacter baumannii has emerged as an important cause of nosocomial infections with increased morbidity and mortality, evidently frequent in intensive care unit (ICU). The unique environment of ICU, artificial ventilation and other invasive procedures, exposure to antibiotics, colonization pressure, and underlying illness facilitate the spread of this species in ICU., ${ }^{1,2}$
A. baumannii has capacity to exchange genetic material which facilitates to acquire antimicrobial resistance determinants among the species $^{3}$. The existence of 45 resistance genes on "resistance island" in MDR Acinetobacter strain indicates their frequency to acquisition of antimicrobial resistant genes. ${ }^{4}$ Overexpression of $b l a_{\mathrm{ADC}}$ by insertion sequence (IS) at the promoter region poses resistance to cephalosporins is inextricably linked to A. baumannii. ${ }^{5,6}$ The dissemination of OXA, VIM, IMP and NDM-1 in this species also poses resistance to the reserve 
antibiotic, carbapenem. Among these enzymes, oxacillinases (OXA-23-like; OXA-24-like; OXA-51-like OXA-58and OXA-143) have emerged globally as the major mechanism of carbapenem resistance in A. baumannii, of which OXA-51 is intrinsic to A. baumannii. ISAbal serves as one of the strong promoters to overexpress the bla OxAs. Recently, New-Delhi metallo-beta-lactamase-1 (NDM-1) among the species has created an additional public health risk, leaving few therapeutic option. ${ }^{7-9}$

Misuse and overuse of antibiotics is extremely common in Bangladesh due to lack of implication of proper guideline regarding the use of antibiotics. Selective pressure of antibiotics in Bangladeshi hospitals allows the preservation of MDR determinants not only in nosocomial pathogens but also in hospital environment. ${ }^{10-11}$ Bangladesh is the prevalent zone of antimicrobial resistance, which has been evidenced by previous studies. Previous reports suggest $A$. baumannii as one of the important nosocomial pathogens in Bangladesh and the resistance determinants are incredibly frequent among the species., ${ }^{72-14}$ To explore the present situation of nosocomial antimicrobial resistance in Bangladesh, this study investigated the resistance profile of nosocomial A. baumannii in Bangladesh. Present study also evaluated the genetic background of resistance to beta-lactam antibiotics among the nosocomial $A$. baumannii in the country.

\section{Materials and Methods}

This study was conducted in the Department of Microbiology of Dhaka Medical College (DMC) between July, 2013 and June, 2014 after getting approval from research review committee (RRC) and ethical review committee (ERC) of DMC according to the Declaration of Helsinki and national and institutional standards. Written consent was taken from all the participants for this study. Patients hospitalized more than 48 hours in ICU were included in this study to evaluate the hospital acquired infections in ICU. ${ }^{15}$ We collected 40 endotracheal aspirates from patients admitted in ICU of Dhaka medical college hospital (DMCH) and 12 A. baumannii strains from Microbiology laboratory of Bangladesh Institute of Research and Rehabilitation in Diabetes, Endocrine and Metabolic disorders (BIRDEM), Dhaka where the Acinetobacter were recovered from tracheal aspirates of ICU patients.

Isolation and Identification of A. baumannii: The microbial growth of endotracheal aspirate was classified as rare, light, moderate or heavy, based on semi quantitative culture on MacConkey agar media $^{16}$ and moderate to heavy growth were considered as significant. ${ }^{17}$ The species of Acinetobacter were first isolated on the basis of gram staining, colony morphology on culture media and several biochemical tests. $A$. baumannii was identified by observing pale colony in MacConkey agar media, gram negative coccobacilli or cocci form in gram stained smear, alkaline slant and butt without $\mathrm{H}_{2} \mathrm{~S}$ or gas production in triple sugar iron agar media, nonmotile, negative indole, urease and oxidase, positive citrate and catalase. ${ }^{18} \mathrm{~A}$. baumannii was confirmed at the species level by detecting

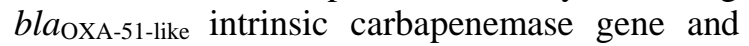
fermentation/oxidation test on Hugh Leifon medium. ${ }^{18-19}$

Antimicrobial susceptibility and phenotypic screening of drug resistance among $A$. baumannii: Antibiotic resistance to commonly used antibiotics was determined by disk diffusion method. ${ }^{20}$ Isolates were considered as MDR, if these were resistant to 3 or more classes of antibiotics among penicillins, cephalosporins, carbapenems, monobactam, aminoglycosides, quinolones, polymyxin. Minimum inhibitory concentration (MIC) of ceftazidime and imipenem was determined by agar dilution method. ${ }^{7}$

Modified three dimensional (MTD) test was used for phenotypic detection of ampC beta-lactamase producers among the A. baumannii which were resistant to both second generation cephalosporin (cefoxitin) and third generation cephalosporin (ceftazidime or cefotaxime). ${ }^{21}$ All the Acinetobacter were tested for extended spectrum beta-lactamase (ESBL) producers by double disc synergy (DDS) test. ${ }^{22}$ Modification of DDS test was done using a piperacillin-tazobactum $(100 / 10 \mu \mathrm{g})$ disc $15 \mathrm{~mm}$ away from cefepime $(30 \mu \mathrm{g})$ disc to investigate the ESBL and ampC co-producers. ${ }^{23}$ Imipenem resistant isolates were screened for MBL producers by DDS test and combined disc (CD) assay. ${ }^{7}$ 
Molecular detection of antimicrobial resistant determinants of $A$. baumannii: The strains were screened for $b l a_{\mathrm{ADC}-\text { like }}$ using $\mathrm{ADC} 1$ and $\mathrm{ADC} 2$ primers. The existence of ISAbal and ISAba125 upstream of $b l a_{\mathrm{ADC}-\text {-like }}$ or presence of any novel IS upstream or downstream of the gene was evaluated by PCR using the primers ISADC1/ ISADC2, 125F/125R, FU/RU and FD/RD.The expected products size $360 \mathrm{bp}$ and $267 \mathrm{bp}$ by FU/RU and FD/RD primer sets were suggested as absence of any novel IS upstream and downstream of the gene, accordingly. ${ }^{24}$ PCR followed by sequencing was designed in this study to observe the presence of any novel IS upstream or downstream of bla $a_{\mathrm{ADC} \text {-like }} \mathrm{A}$ multiplex PCR was performed to screen the presence of six families of plasmid mediated ampC $\beta$-lactamases (MOX, CIT, DHA, ACC, EBC and FOX group). ${ }^{25}$ To investigate the mechanism of carbapenem resistance, bla $a_{\mathrm{KPC}}$, bla $_{\mathrm{IMP}}$, bla $_{\mathrm{VIM}}, b a_{\mathrm{NDM}-1}$ and bla $a_{\mathrm{OXA}-51,23,40,58}$ and 143 were examined among all the isolates. ${ }^{8,26-28}$

To screen the presence of ISAbal at the upstream of bla OXA-51, 23, 40, 58 and 143, PCR was designed using forward primer of ISAbal and reverse primers of blaOXA-51, 23, 40, 58 and 143

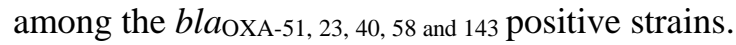

Table I: Distribution of beta-lactamase genes among the 25 A. baumannii resistant to different antibiotic agents

\begin{tabular}{|c|c|c|c|c|c|c|c|c|c|c|c|c|c|}
\hline \multirow[t]{2}{*}{ RG } & \multirow{2}{*}{$\begin{array}{c}\mathbf{D} \\
\mathbf{n} \\
(\%)\end{array}$} & \multicolumn{12}{|c|}{ Antimicrobial resistance profile } \\
\hline & & AMC & $\mathrm{CZ}$ & $\mathrm{CX}$ & CEP & CEX & $\overline{\mathrm{AK}}$ & CIP & $\mathrm{IM}$ & $\mathrm{S}-\mathrm{C}$ & $\mathrm{CL}$ & $\mathrm{P}-\mathrm{T}$ & $\overline{\mathrm{AZ}}$ \\
\hline $\begin{array}{l}b^{b l a_{\mathrm{A}}} \\
\text { DC-like }\end{array}$ & $\begin{array}{c}23 \\
(92)\end{array}$ & $\begin{array}{c}23 \\
(100)\end{array}$ & $\begin{array}{c}23 \\
(100)\end{array}$ & $\begin{array}{c}23 \\
(100)\end{array}$ & $\begin{array}{c}21 \\
(91.30)\end{array}$ & $\begin{array}{c}23 \\
(100)\end{array}$ & $\begin{array}{c}21 \\
(91.30)\end{array}$ & $\begin{array}{c}23 \\
(100)\end{array}$ & $\begin{array}{c}21 \\
(91.30)\end{array}$ & $\begin{array}{c}13 \\
(56.52)\end{array}$ & $0(0)$ & $\begin{array}{c}22 \\
(95.65)\end{array}$ & $\begin{array}{c}10 \\
(43.48)\end{array}$ \\
\hline CIT & $\begin{array}{c}1 \\
(4)\end{array}$ & $\begin{array}{c}1 \\
(100)\end{array}$ & $\begin{array}{c}1 \\
(100)\end{array}$ & $\begin{array}{c}1 \\
(100)\end{array}$ & $\begin{array}{c}1 \\
(100)\end{array}$ & $\begin{array}{c}1 \\
(100)\end{array}$ & $\begin{array}{c}0 \\
(0)\end{array}$ & $\begin{array}{c}1 \\
(100)\end{array}$ & $\begin{array}{c}1 \\
(100)\end{array}$ & $\begin{array}{c}1 \\
(100)\end{array}$ & $0(0)$ & $\begin{array}{c}1 \\
(100)\end{array}$ & $\begin{array}{c}0 \\
(0)\end{array}$ \\
\hline $\begin{array}{l}\text { DH } \\
\text { A }\end{array}$ & $\begin{array}{c}6 \\
(24)\end{array}$ & $\begin{array}{c}6 \\
(100)\end{array}$ & $\begin{array}{c}6 \\
(100)\end{array}$ & $\begin{array}{c}6 \\
(100)\end{array}$ & $\begin{array}{c}6 \\
(100)\end{array}$ & $\begin{array}{c}6 \\
(100)\end{array}$ & $\begin{array}{c}6 \\
(100)\end{array}$ & $\begin{array}{c}6 \\
(100)\end{array}$ & $\begin{array}{c}5 \\
(83.3 \%)\end{array}$ & $\begin{array}{c}5 \\
(83.3 \%)\end{array}$ & $0(0)$ & $\begin{array}{c}6 \\
(100)\end{array}$ & $\begin{array}{c}1 \\
(16.67)\end{array}$ \\
\hline $\begin{array}{l}\mathrm{AC} \\
\mathrm{C}\end{array}$ & $\begin{array}{c}2 \\
(8)\end{array}$ & $\begin{array}{c}2 \\
(100)\end{array}$ & $\begin{array}{c}2 \\
(100)\end{array}$ & $\begin{array}{c}2 \\
(100)\end{array}$ & $\begin{array}{c}1 \\
(50)\end{array}$ & $\begin{array}{c}2 \\
(100)\end{array}$ & $\begin{array}{c}2 \\
(100)\end{array}$ & $\begin{array}{c}2 \\
(100)\end{array}$ & $\begin{array}{c}2 \\
(100)\end{array}$ & $\begin{array}{c}0 \\
(0)\end{array}$ & $0(0)$ & $\begin{array}{c}1 \\
(50)\end{array}$ & $\begin{array}{c}1 \\
(50)\end{array}$ \\
\hline EBC & $\begin{array}{c}21 \\
(84)\end{array}$ & $\begin{array}{c}20 \\
(95.24)\end{array}$ & $\begin{array}{c}20 \\
(95.24)\end{array}$ & $\begin{array}{c}20 \\
(95.24)\end{array}$ & $\begin{array}{c}18 \\
(85.71)\end{array}$ & $\begin{array}{c}20 \\
(95.24)\end{array}$ & $\begin{array}{c}18 \\
(85.71)\end{array}$ & $\begin{array}{c}20 \\
(95.24)\end{array}$ & $\begin{array}{c}20 \\
(95.24)\end{array}$ & $\begin{array}{c}10 \\
(47.62)\end{array}$ & $0(0)$ & $\begin{array}{c}19 \\
(90.48)\end{array}$ & $\begin{array}{c}9 \\
(42.86)\end{array}$ \\
\hline $\begin{array}{l}b^{b l a} a_{0} \\
\text { XA-51 }\end{array}$ & $\begin{array}{c}25 \\
(100)\end{array}$ & $\begin{array}{c}24 \\
(96)\end{array}$ & $\begin{array}{c}24 \\
(96)\end{array}$ & $\begin{array}{c}24 \\
(96)\end{array}$ & $\begin{array}{c}22 \\
(88)\end{array}$ & $\begin{array}{c}24 \\
(96)\end{array}$ & $\begin{array}{c}22 \\
(88)\end{array}$ & $\begin{array}{c}24 \\
(96)\end{array}$ & $\begin{array}{c}22 \\
(88)\end{array}$ & $\begin{array}{c}13 \\
(52)\end{array}$ & $0(0)$ & $\begin{array}{c}23 \\
(92)\end{array}$ & $\begin{array}{c}10 \\
(40)\end{array}$ \\
\hline blao & 19 & 18 & 18 & 18 & 17 & 18 & 18 & 18 & 17 & 10 & 0 & 17 & 7 \\
\hline XA-23 & (76) & $(94.74)$ & $(94.74)$ & $(94.74)$ & $(89.47)$ & $(94.74)$ & $(94.74)$ & $(94.74)$ & $(89.47)$ & $(52.63)$ & (0) & $(89.47)$ & $(36.84)$ \\
\hline $\begin{array}{l}\text { blao } \\
\mathrm{XA}-58\end{array}$ & $\begin{array}{c}4 \\
(16)\end{array}$ & $\begin{array}{c}4 \\
(100)\end{array}$ & $\begin{array}{c}4 \\
(100)\end{array}$ & $\begin{array}{c}4 \\
(100)\end{array}$ & $\begin{array}{c}3 \\
(75)\end{array}$ & $\begin{array}{c}4 \\
(100)\end{array}$ & $\begin{array}{c}4 \\
(100)\end{array}$ & $\begin{array}{c}4 \\
(100)\end{array}$ & $\begin{array}{c}4 \\
(100)\end{array}$ & $\begin{array}{c}2 \\
(50)\end{array}$ & $\begin{array}{c}0 \\
(0)\end{array}$ & $\begin{array}{c}3 \\
(75)\end{array}$ & $\begin{array}{c}3 \\
(75)\end{array}$ \\
\hline $\begin{array}{l}\text { bla }_{\mathrm{K}} \\
\mathrm{PC}\end{array}$ & $\begin{array}{c}11 \\
(44)\end{array}$ & $\begin{array}{c}11 \\
(100)\end{array}$ & $\begin{array}{c}11 \\
(100)\end{array}$ & $\begin{array}{c}11 \\
(100)\end{array}$ & $\begin{array}{c}11 \\
(100)\end{array}$ & $\begin{array}{c}11 \\
(100)\end{array}$ & $\begin{array}{c}9 \\
(81.82)\end{array}$ & $\begin{array}{c}11 \\
(100)\end{array}$ & $\begin{array}{c}11 \\
(100)\end{array}$ & $\begin{array}{c}7 \\
(63.64)\end{array}$ & $0(0)$ & $11(100)$ & $\begin{array}{c}7 \\
(63.64)\end{array}$ \\
\hline $\begin{array}{l}\text { bla }_{\mathrm{VI}} \\
\mathrm{M}\end{array}$ & $\begin{array}{c}18 \\
(72)\end{array}$ & $\begin{array}{c}18 \\
(100)\end{array}$ & $\begin{array}{c}18 \\
(100)\end{array}$ & $\begin{array}{c}18 \\
(100)\end{array}$ & $\begin{array}{c}15 \\
(93.75)\end{array}$ & $\begin{array}{c}18 \\
(100)\end{array}$ & $\begin{array}{c}15 \\
(93.75)\end{array}$ & $\begin{array}{c}18 \\
(100)\end{array}$ & $\begin{array}{c}16 \\
(88.89)\end{array}$ & $\begin{array}{c}8 \\
(44.44)\end{array}$ & $0(0)$ & $\begin{array}{c}15 \\
(93.75)\end{array}$ & $\begin{array}{c}6 \\
(33.33)\end{array}$ \\
\hline $\begin{array}{l}b l a_{N} \\
\text { DM-1 }\end{array}$ & $\begin{array}{c}23 \\
(92)\end{array}$ & $\begin{array}{c}22 \\
(95.65)\end{array}$ & $\begin{array}{c}22 \\
(95.65)\end{array}$ & $\begin{array}{c}22 \\
(95.65)\end{array}$ & $\begin{array}{c}20 \\
(86.96)\end{array}$ & $\begin{array}{c}22 \\
(95.65)\end{array}$ & $\begin{array}{c}20 \\
(86.96)\end{array}$ & $\begin{array}{c}22 \\
(95.65)\end{array}$ & $\begin{array}{c}22 \\
(95.65)\end{array}$ & $\begin{array}{c}12 \\
(52.17)\end{array}$ & $0(0)$ & $\begin{array}{c}21 \\
(91.30)\end{array}$ & $\begin{array}{c}8 \\
(34.78)\end{array}$ \\
\hline
\end{tabular}

*Abbreviations: RG, resistant gene; D, distribution of $b a_{\mathrm{ampC}}$ bla $a_{\mathrm{KPC}}$ and bla $\mathrm{a}_{\mathrm{MBLs}}$ among 25 A baumannii; AMC, Amoxiclav; CZ, Ceftazidime; CX, Cefotaxime; CEP, Cefepime; CEX, Cefoxitin; AK, Amikacin; CIP, Ciprofloxacin; IM, Imipenem; S-C, Sulbactamcefoperazone; CL, Colistin; P-T, Piperacillin-Tazobactam; AZ, Aztreonam

\section{Results}

Among the 40 samples collected from ICU of $\mathrm{DMCH}, 38$ organisms were recovered of which 13 (32.5\%) were Acinetobacter, 6 (15\%) were Pseudomonas aeruginosa, 6 (15\%) were Klebsiella pneumoniae, 3 (7.5\%) were Klebsiella oxytoca, 3 (7.5\%) were Staphylococcus aureus.

A total of 25 Acinetobacter was included in this study. All the 25 isolated Acinetobacter were identified as $A$. baumannii by detecting bla OXA-51- $^{-}$ like $^{19}$ and several biochemical tests. ${ }^{18}$

Twenty-four (96\%) A. baumannii were considered as MDR. Ninety-six percent $A$. baumannii were resistant to amoxiclav, ceftazidime, ciprofloxacin and cefoxitin, $92 \%$ to cefotaxime and piperacillin-tazobactam, $88 \%$ to cefepime, amikacin and imipenem, $52 \%$ to sulbactam-cefoperazone and $40 \%$ were resistant to aztreonam. Among the MDR isolates, 20 $(83.33 \%)$ and $4(16.67 \%)$ were resistant to seven classes of antibiotics and 6 classes of antibiotics, respectively. However, all were sensitive to colistin.

No A. baumannii was detected as ESBL producer both by DDS test and modified DDS test. MTDT and PCR identified $9(37.5 \%)$ and $23(95.83 \%)$ of the cefoxitin and ceftazidime and/or cefotaxime resistant isolates as ampC producers, 
respectively. Twenty-three $(95.83 \%)$ of the 24 cephalosporin resistant $A$. baumanni had the chromosomal bla $a_{\mathrm{ADC}}$, of which 10 (43.48\%) showed positive result for the presence of ISAbal upstream of the gene, while all $(100 \%)$ the bla $_{\mathrm{ADC}}$ harboring strains were positive for ISAba125 upstream of the gene. ISAba125 is also present in the isolates having no bla $a_{\mathrm{ADC}}$. The primer sets FU/RU and FD/RD amplified specific region of $360 \mathrm{bp}$ and $267 \mathrm{bp}$, respectively in all the isolates having $b l a_{\mathrm{ADC}}$. These results indicated the dearth of any novel IS upstream and downstream of the gene in our isolates. Simultaneous production of plasmid mediated ampC beta-lactamases was observed in all $b l a_{\mathrm{ADC}}$ positive strains. In this study the predominant acquired ampC was the $\mathrm{EBC}$ group (84\%), followed by DHA (24\%), ACC (8\%) and CIT (4\%) among the 25 A. baumannii (Table II). The MIC of ceftazidime among the ampC producers ranged from $\geq 256 \mu \mathrm{g} / \mathrm{ml}$ to $128 \mu \mathrm{g} / \mathrm{ml}$. One of the 24 cephalosporin resistant $A$. baumanni had neither $b a_{\mathrm{ADC}}$ nor any plasmid mediated $b l a_{\mathrm{ampC}}$, having $128 \mu \mathrm{g} / \mathrm{ml}$ MIC of ceftazidime. Twenty-two (91.67\%) of the 24 cephalosporin resistant isolates were concurrently resistant to imipenem and all had the bla ampc. However, one cephalosporin sensitive A. baumannii was positive for EBC group.

Table II: The association of $b l a_{\mathrm{NDM}-1}$ with other resistance genes $(\mathrm{n}=23)$

\begin{tabular}{lc}
\hline \multicolumn{1}{c}{$\begin{array}{c}\text { Resistance gene with } \\
\text { bla } a_{\mathrm{NDM}-1}\end{array}$} & $\begin{array}{c}\text { Association with } \text { bla }_{\mathrm{NDM}-1} \\
\mathrm{n}(\%)\end{array}$ \\
\hline bla $_{\mathrm{OXA}-51}$ & $23(100)$ \\
bla $_{\mathrm{OXA}-23}$ & $19(82.60)$ \\
bla $_{\mathrm{OXA}-58}$ & $3(13.04)$ \\
bla $_{\mathrm{VIM}}$ & $17(73.92)$ \\
bla $_{\mathrm{KPC}}$ & $10(43.48)$ \\
bla $_{\mathrm{ADC}}$ & $21(91.30)$ \\
Plasmid mediated ampC & $21(91.30)$ \\
ISAba125 & $23(100)$ \\
\hline
\end{tabular}

About $86.36 \%$ and $72.27 \%$ of imipenem resistant organisms were considered as MBL producers by CD assay and DDS test, respectively. Overall 21 $(95.45 \%)$ and $11(50 \%)$ of the 22 imipenem resistant isolates were positive for bla $a_{\mathrm{MBLs}}$ and bla $a_{\mathrm{KPC}}$ by PCR, respectively. Carbapenem hydrolyzing NDM-1 and VIM were present in $95.45 \%$ and $72.73 \%$ of imipenem resistant $A$. baumannii, respectively. MIC of imipenem among the $21 \mathrm{MBL}$ producers ranged from $256 \mu \mathrm{g} / \mathrm{ml}$ to $16 \mu \mathrm{g} / \mathrm{ml}$. No bla $a_{\mathrm{MBL}}$ was found in one of the imipenem resistant isolate which was highly resistant to imipenem (MIC: $256 \mu \mathrm{g} / \mathrm{ml}$ ) and had the $b l a_{\mathrm{KPC}}$. The intrinsic oxacillinase, $b l a_{\text {OXA-51 }}$ was positive in all $(100 \%)$ and acquired oxacillinase, bla $a_{\text {OXA-23 }}$ and bla $a_{\text {OXA-58 }}$ were present in $17(77.27 \%)$ and $4(18.18 \%)$ of imipenem resistant A. baumannii, accordingly. ISAbal at the upstream of the bla ${ }_{\text {OXA-51 }}$ was present in 5 (22.72\%) of 22 imipenem resistant isolates and MIC of imipenem among the five isolates ranged from $128 \mathrm{ul} / \mathrm{ml}$ to $32 \mathrm{ul} / \mathrm{ml}$. This study did not observe the presence of ISAbal at the upstream of the $b l a_{\text {OXA-23 }}$ and $b l a_{\text {OXA-58. }}$.

The distribution of beta-lactamase genes and their relationship with antibiotic resistance in this study are depicted in Table I. Present study did not found any MOX and FOX family of betalactamase, bla OXA-24, $_{\text {bla }}$ OXA-143 and bla IMP. The presence of several resistance genes in single isolate was observed in this study. The association of $b l a_{\mathrm{NDM}-1}$ with other resistance genes is shown in Table II. Regardless of imipenem susceptibility, one of the 25 isolates had combination of bla $a_{\mathrm{VIM}}$, bla $_{\mathrm{OXA}-23}$ and bla $a_{\mathrm{NDM}}$ 1 , one carried the combination of bla $\mathrm{VIM}$ and bla $_{\mathrm{OXA}-23}$ and one had bla $_{\mathrm{NDM}-1}$.

\section{Discussion}

In recent time, MDR A. baumannii has appeared to be one of vital causes of nosocomial outbreaks in ICU throughout the world. ${ }^{1,2}$ The propensity of multidrug resistance was also observed formerly among A. baumanni in Bangladeshi hospitals. ${ }^{13-14}$ In the present study, $96 \%$ of the $A$. baumannii were identified as MDR recovered from ICU patients. In this study, all the MDR isolates are shown to be resistant to $\geq 6$ classes of antibiotics except colistin. A broad array of betalactamses has been reported in these organisms as the most prevalent mechanism of resistance to beta-lactams. ${ }^{3,5,6}$

Carbapenem resistance in Acinetobacter is in increasing trend worldwide. ${ }^{3,9}$ Though the most prevalent mechanism of carbapenem resistance in A. baumannii is the production of oxacillinases, they are weak carbapenem hydrolyser in absence of promoters. ${ }^{8}$ In this study, both chromosomal bla OxA-51 $(100 \%)$ and acquired oxacillinases such as bla $a_{\text {OXA-23 }}(77.27 \%)$ and bla $a_{\text {OXA-58 }}(18.18 \%)$ were found in imipenem 
resistant A. baumannii. However, only the bla ${ }_{\text {OXA-51 was associated with ISAbal in } 22.72 \%}$ imipenem resistant isolates.

Molecular assessment in this study explicating the major mechanism of carbapenem resistance was the presence of bla $a_{\mathrm{NDM}-1}(95.45 \%)$ in imipenem resistant A. baumannii. NDM-1 producing A. baumannii has been reported since 2010 with a high prevalence in Indian subcontinent ${ }^{9}$. Our data suggest the increase in prevalence (from $22.86 \%$ to $95.45 \%$ ) of bla $a_{\mathrm{NDM}-1}$ among the imipenem resistant isolates in Bangladesh. $^{7}$ Though $b l a_{\mathrm{NDM}-1}$ was initially reported on plasmid of Enterobacteriaceae, later report of bla NDM-1 in $A$. baumannii on conjugative plasmid of varying size $(30-50 \mathrm{~kb})$ implies the inter species dissemination of this resistance determinant. The high level of inter lineage and inter species transfer of this gene are thought to be likelihood of global spread of this gene. The association of high number of resistance genes such as bla $a_{\mathrm{OXA}-48}, b l a_{\mathrm{VIM}}$, bla $a_{\text {ESBLs, }}$ plasmid-mediated cephalosporinase genes, 16S RNA methylases genes, esterase genes, rifampin modifying genes and sulfamethoxazole resistance genes in NDM-1 positive bacteria pose a significant public health threat worldwide. ${ }^{9,29}$ The existence of bla $a_{\mathrm{VIM}}$, $b^{b l a_{\mathrm{KPC}}}, b a_{\mathrm{OXA}-51}, b l a_{\mathrm{OXA}-23}, b l a_{\mathrm{OXA}-58}, b l a_{\mathrm{ADC}}$ and plasmid mediated ampC in NDM-1 positive strains (Table II) and their antimicrobial resistance profile (Table I) in this study confirms the association of bla $a_{\mathrm{NDM}-1}$ with several resistance genes, which coincides with previous observations. The level of resistance to carbapenem may vary ranging from $0.5 \mathrm{mg} / \mathrm{l}$ to $>64 \mathrm{mg} / \mathrm{l}$ in spite of presence of carbapenemase including NDM-1 ${ }^{29}$. Present report is not an exception, which was revealed by presence of combination of bla $a_{\mathrm{VIM}}, b a_{\mathrm{OXA}-23}$ and bla $_{\mathrm{NDM}-1}$ in one and the combination of bla $a_{\mathrm{VIM}}$ and bla $_{\text {oxa-23 }}$ in one and $b l a_{\mathrm{NDM}-1}$ in one imipenem sensitive $A$. baumannii. The insertional element ISAba125 is widely distributed in A. baumannii and poses carbapenem resistance by insertional inactivation of CarO outer membrane protein. ${ }^{30}$ In addition, the location of $b l a_{\mathrm{NDM}-1}$ between two direct repeats of the ISAba125 element is dependable for possible expression and dissemination of this gene. ${ }^{9}$ The concomitant presence of bla $a_{\mathrm{NDM}-1}$ and ISAba125 was also shown in this study (Table II). Hence the presence of ISAbal25 in all carbapenem resistant $A$. baumanni in our study explains one of the possible mechanisms of reduced susceptibility to carbapenem.

The existence of $b l a_{\mathrm{MBLs}}$ poses resistance to carbapenem in addition to cephalosporin. ${ }^{3}$ However, we screened production of ampC betalactamases and ESBL among our strains as coexisting cause of cephalosporin resistance. Our study found high level of ceftazidime resistance among all the cephalosporin resistant isolates (MIC ranged from $\geq 256 \mu \mathrm{g} / \mathrm{ml}$ to $128 \mu \mathrm{g} / \mathrm{ml}$ ). In this study, $95.83 \%$ of the cephalosporin resistant organisms had both ADC and at least one plasmid mediated ampC enzymes. Though plasmid mediated ampC beta-lactamses previously reported among the members of Enterobacteriaceae, ${ }^{31-34}$ this is the first report of plasmid mediated ampC enzymes in $A$. baumannii. Most strains producing plasmid mediated ampC have been isolated from patients having history of prolong stay in ICU, invasive surgical procedures and underlying illness such as leukemia or cancer. ${ }^{35}$ The presence of these enzymes in $A$. baumannii indicates the dissemination of these genes in the hospital settings of Bangladesh and suggests a potential risk for hospital outbreaks in the country. The enzyme of EBC family was reported previously in Asia in K. pneumoniae. ${ }^{32}$ This study detected a dominance of EBC group in A. baumannii followed by DHA, ACC and CIT in Bangladesh, while the prevalent enzymes in the members of Enterobacteriaceae are the DHA and CMY groups. ${ }^{33-34} \mathrm{We}$ also determined the overexpression of bla $_{\mathrm{ADC}}$ by screening ISAbal in $43.48 \%$ and ISAba125 in $100 \%$ of ADC producing organisms which are the major machinery of cephalosporin resistance in $A$. baumannii, as reported previously. ${ }^{3,6}$ ISAba125 has greater ability to overproduce ADC than ISAbal suggest the possible overproduction of ADC due to ISAbal25 among our strains. ${ }^{24}$ As no ESBL producer was detected by phenotypic method, the genes for $b l a_{\mathrm{ESBLs}}$ were not studied.

Antimicrobial resistance is thought to be a leading issue for the dissemination of nosocomial infections. Due to lack of proper policy, this issue has become more threatening in developing countries day by day. ${ }^{36}$ The worrying scenario was also observed in Bangladesh, which was reflected by our present data including our previous studies. ${ }^{7,12}$ The isolates showed resistance to most of the antimicrobials. The 
most effective antimicrobial agent was colistin in our studied A. baumannii, irrespective of types of existing beta-lactamase genes. Aztreonam (60\%) followed by sulbactam-cefoperazone $(48 \%)$ sensitivity was observed to some extents in this study (Table II). This resistance profile of nosocomial Acinetobacter is very alarming, as there are a few reserve antimicrobials to manage the hospitalized patients in Bangladesh. MDR A. baumannii serves as reservoir of nosocomial infections due to its remarkable capability to achieve resistance determinants. ${ }^{4}$ Therefore, the multidrug resistance profile in our study demands urgent systemic surveillance of antimicrobial resistance in Bangladesh to know the exact epidemiology of resistant determinant in the country in order to develop standard infection control strategies in Bangladeshi hospitals.

Conclusion: Though antimicrobial resistance is now one of the important emerging public health problems in Bangladesh, there is no standard policy regarding use of antibiotics in health care settings in the country. ${ }^{10}$ We detected $96 \%$ A. baumannii as MDR. The distribution of antimicrobial resistance genes such as $b l a_{\mathrm{ampC}}$ (both chromosomal and plasmid mediated) and carbapenemase genes (bla $a_{\mathrm{MBLs}}$ and bla $\left.a_{\mathrm{KPC}}\right)$ were observed among $95.83 \%$ cephalosporin resistant A. baumanni and all (100\%) imipenem resistant isolates, respectively. This is the first reported acquired ampC beta-lactamases in this organism. Results of this study indicate the occurrence of spreading resistant determinants in Bangladeshi hospitals. It is expected that these results will help to direct a standard guideline of rational antimicrobials use and infection control strategy in Bangladesh.

\section{References}

1. Falgas ME, Koletsi PK, Blizitosis IA. The diversity of definitions of multi-drug resistant (MDR) and pandrug resistant (PDR) Acinetobacter baumannii and Pseudomonas aeruginosa. J Med Microbiol 2006; 55: 1619-29.

2. Tripathi PC, Gajbhiye SR, Agrawal GN. Clinical and antimicrobial profile of Acinetobacter spp.: An emerging nosocomial superbug. Adv Biomed Res 2014; 3: 13 .

3. Garnacho-Montero J, Amaya-Villar R. Multiresistant Acinetobacter baumannii infections: epidemiology and management. Curr Opin Infect Dis 2010; 23: 332-39.
4. Fournier PE, Vallenet D, Barbe V, Audic S, Ogata $\mathrm{H}$, Poirel L, et al. Comparative genomics of multidrug resistance in Acinetobacter baumannii. PLoS Genet 2006; 2: e7. Available: [http://journals.plos.org/plosgenetics/article?id=10.1 371/journal. pgen.0020007] Accessed on 14 April 2016.

5. Bou G, Martinez-Beltran J. Cloning, nucleotide sequencing and analysis of the gene encoding an AmpC beta-lactamase in Acinetobacter baumannii. Antimicrob Agents Chemother 2000; 44: 428-32.

6. Hujer KM, Hamza NS, Hujer AM, Perez F, Helfand MS, Bethel CR, et al. Identification of anew allelic variant of the Acinetobacter baumannii cephalosporinase, ADC-7 beta-lactamase: defining a unique family of class $\mathrm{C}$ enzymes. Antimicrob Agents Chemother 2005; 49: 2941-48.

7. Farzana R, Shamsuzzaman SM, Mamun KZ. Isolation and moleculer characterization of New Delhi metallo-beta-lactamase-1 producing superbug in Bangladesh. J Infect Dev Ctries 2013; 7: 161-68.

8. Elabd FM, Al-Ayed MSZ, Asaad AM, Alsareii SA, Qureshi MA, Musa HA. Molecular characterization of oxacillinases among carbapenem-resistant Acinetobacter baumannii nosocomial isolates in a Saudi hospital. J Infect Public Health 2015; 8: 24247.

9. Johnson AP, Woodford N. Global spread of antibiotic resistance: the example of New Delhi metallo- $\beta$-lactamase (NDM)-mediated carbapenem resistance. J Med Microbiol 2013; 62:499-13.

10. Prevention and Containment of Antimicrobial resistance. Available:

[http://www.ino.searo.who.int/LinkFiles

/Other_Content_WHD11-Seminar_Presentation-

WRpdf] Accessed on 11 April 2015.

11. Hasan B, Drobni P, Drobni M, Alam M, Olsen B. Dissemination of NDM-1. Lancet Infect Dis 2012; 12: $99-100$.

12. Farzana R, Shamsuzzaman SM, Mamun KZ, Shears P. Antimicrobial susceptibility pattern of extended spectrum beta-lactamase producing gram-negative bacteria isolated from wound and urine in a tertiary care hospital, Dhaka City, Bangladesh. Southeast Asian J Trop Med Public Health 2013; 44:96-103

13. Islam MA, Talukdar PK, Hoque A, Huq M, Nabi A, Ahmed D, et al. Emergence of multidrug-resistant NDM-1-producing Gram-negative bacteria in Bangladesh. Eur J Clin Microbiol Infect Dis 2012; 31:2593-600.

14. Mansur FJ, Barai L, Karim MM, Haq JA, Fatema K, Faruq MO. Intravascular catheter related infections and antimicrobial susceptibility pattern of isolated bacteria in a tertiary care hospital of Bangladesh. Indian J Med Microbiol 2014; 32: 68-71. 
15. Garner JS, Jarvis WR, Emori TG, Horan TC, Hughes JM. CDC definitions for nosocomial infections, 1988. Am J Infect Control 1988; 16: 12840.

16. Fujitani S, Cohen-Melamed MH, Tuttle RP, Delgado E, Taira Y, Darby JM. Comparison of Semi-Quantitative Endotracheal Aspirates to Quantitative Non-Bronchoscopic Bronchoalveolar Lavage in Diagnosing Ventilator-Associated Pneumonia. Respir Care 2009; 54: 1453-61.

17. Craven DE, Chroneou A, Zias N, Hjalmarson KI. Ventilator-Associated Tracheobronchitis. The impact of targeted antibiotic therapy on patient outcomes. Chest 2009; 135: 521-28.

18. Constantiniu S, Romaniue A, Lancu LS, Filimon R, Tarasi I. Cultural and biochemical characteristics of Acinetobacter spp. strains isolated from hospital units. J Prevent Med 2004; 12: 35-42.

19. Turton JF, Woodford N, Glover J, Yarde S, Kaufmann ME, Pitt TL. Identification of Acinetobacter baumannii by detection of the blaoxA51-like carbapenemase gene intrinsic to this species. J Clin Microbiol 2006; 44: 2974-76.

20. Bauer AW, Kirby WMM, Sheris JC, Truck M. Antibiotic susceptibility testing by a standardized single disc method. Am J Clin Pathol 1996; 145: 225-30.

21. Manchanda V, Singh NP. Occurence and detection of AmpC beta-lactamases among gram-negative clinical isolates using a modified three dimentional test at Guru Tegh Bahadur Hospital, Delhi, India. J Antimicrob Chemother 2003; 51: 415-18.

22. Jarlier V, Nicolas M, Fournier G, Philippon A. Extended spectrum beta-lactamases conferring transferable resistance to newer beta-lactama agents in Enterobacteriaceae: Hospital prevalence and susceptibility patterns. Rev Infect Dis 1988; 10: 867-78.

23. Khan M, Thukral SS, Gaind R. Evaluation of a modified double-disc synergy test for detection of extended spectrum beta-lactamases in AmpC betalactamase-producing Proteus mirabilis. Indian J Med Microbiol 2008; 26: 58-61.

24. Lopes BS, Amyes SG. Role of ISAbal and ISAba125 in governing the expression of blaADC in clinically relevant Acinetobacter baumannii strains resistant to cephalosporins. J Med Microbiol 2012; 61: 1103-08.

25. Pérez-Pérez FJ, Hanson ND. Detection of plasmidmediated AmpC beta-lactamase genes in clinical isolates by using multiplex PCR. J Clin Microbiol 2002; 40:2153-62.

26. Robledo IE, Aquino EE, Sante MI, Santana JL, Otero DM, Leon CF, et al. Detection of KPC in Acinetobacter spp. in Puerto Rico. Antimicrob Agents Chemother 2010; 54: 1354-57.
27. Mesli E, Berrazeg M, Drissi M, Bekkhoucha SN, Rolain JM. Prevalence of carbapenemase-encoding genes including New Delhi metallo- $\beta$-lactamase in Acinetobacter species, Algeria. Int J Infect Dis 2013; 17: e739-43.

28. Higgins PG, Poirel L, Lehmann M, Nordmann P, Seifert H. OXA-143, a novel carbapenemhydrolyzing class D $\beta$-lactamase in Acinetobacter baumannii. Antimicrob Agents Chemother 2009; 53: 5035-38.

29. Nordmann P, Naas T, Poirel L. Global spread of Carbapenemase-producing Enterobacteriaceae. Emerg Infect Dis 2011; 17: 1791-98.

30. Mussi MA, Limansky AS, Viale AM. Acquisition of resistance to carbapenems in multidrug-resistant clinical strains of Acinetobacter baumannii: natural insertional inactivation of a gene encoding a member of a novel family of beta-barrel outer membrane proteins. Antimicrob Agents Chemother 2005; 49: 1432-40.

31. Gazouli M, Tzouvelekis LS, Prinarakis E, Miriagou V, Tzelepi E. Transferable cefoxitin resistance in enterobacteria from Greek hospitals and characterization of a plasmid-mediated group 1 betalactamase (LAT-2). Antimicrob Agents Chemother 1996; 40: 1736-40.

32. Song W, Kim JS, Kim HS, Yong D, Jeong SH, Park $\mathrm{MJ}$, et al. Increasing trend in the prevalence of plasmid-mediated AmpC beta-lactamases in Enterobacteriaceae lacking chromosomal ampC gene at a Korean university hospital from 2002 to 2004. Diagn Microbiol Infect Dis 2006; 55:219-24.

33. Yum JH, Kim S, Lee H, Yong D, Lee K, Cho SN, et al. Emergence and wide dissemination of CTX-Mtype ESBLs, and CMY-2- and DHA-1-type AmpC beta-lactamases in Korean respiratory isolates of Klebsiella pneumoniae. J Korean Med Sci 2005; 20: 961-65.

34. Singtohin S, Chanawong A, Lulitanond A, Sribenjalux P, Auncharoen A, Kaewkes W, et al. CMY-2, CMY-8b, and DHA-1 plasmid-mediated AmpC $\beta$-lactamases among clinical isolates of Escherichia coli and Klebsiella pneumoniae from a university hospital, Thailand. Diagn Microbiol Infect Dis 2010; 68: 271-77.

35. Philippon A, Arlet G, Jacoby GA. Plasmiddetermined AmpC-type beta-lactamases. Antimicrob Agents Chemother 2002; 46: 1-11.

36. Rossolini GM, Mantengoli E, Docquier JD, Musmanno RA, Coratza G. Epidemiology of infections caused by multiresistant gram-negatives: ESBLs, MBLs, panresistant strains. New Microbiol 2007; 30: 332-39. 